\title{
PENGARUH PERSEPSI SISWA TENTANG IKLIM SEKOLAH DAN KEMANDIRIAN BELAJAR TERHADAP HASIL BELAJAR SISWA PADA MATA PELAJARAN EKONOMI KELAS XI IPS SMA N 1 PARIANGAN
}

\author{
AlfattoryRheza Syahrul ${ }^{1}$ Afifatul Musrifa ${ }^{2}$ \\ Dosen Program Studi Pendidikan Ekonomi STKIP- PGRI Sumbar \\ Jl. Gunung Pangilun No.1, Padang Sumatera Barat \\ Email :alfattory_r@yahoo.com
}

Submitted: 2016.06.21 Reviewed: 2016.07.01 Accepted: 2016.07.01

http://dx.doi.org/10.22202/economica.2016.v4.i2.634

\begin{abstract}
This study aimed to analyze the influence of students perceptions of teacher classroom management, school climate and independence of learning on student learning outcomes on economic subjects in class XI IPS 1 Pariangan. The result indicate that: (1) there is a positive and significant influence between scholl climate on learning outcomes of students in grade XI IPS SMAN 1 Pariangan, shown with a coefficient of 0,244 with a $t_{\text {count }}$ of 4,184 >t table 1,99045 (2) there is a positive and significant influence between independent learning on learning outcomes of students in grade XI IPS SMAN 1 Pariangan, shown with a coefficient of 0,163 with a $t_{\text {count }}$ of $2,371>t_{\text {table }} 1,99045$.
\end{abstract}

\begin{abstract}
Abstrak
Penelitian ini bertujuan untuk menganalisis pengaruh persepsisiswa tentang iklim sekolah dan kemandirian belajar terhadap hasil belajar siswa pada mata pelajaran ekonomi kelas XI IPS SMA N 1 Pariangan. Hasil penelitian menunjukkan bahwa: 1) Terdapat pengaruh yang positif dan signifikan antara iklim sekolah terhadap hasil belajar ekonomi siswa kelas XI IPS SMA N 1 Pariangan, ditunjukkan dengan nilai koefisien sebesar 0,244 dengan nilai $t_{\text {hitung }}$ sebesar 4,184> $t_{\text {tabel }}$ 1,99045. 2) Terdapat pengaruh yang positif dan signifikan antara kemandirianbelajar terhadaphasil belajar ekonomi siswa kelas XI IPS SMA N 1 Pariangan, ditunjukkan dengan nilai koefisien sebesar 0,163 dengan nilai $t_{\text {hitung }}$ sebesar 2,371> $t_{\text {tabel }} 1,99045$.
\end{abstract}

Keywords: Learning Result,Climeta Learning and independence learning 


\section{PENDAHULUAN}

Pendidikan merupakan suatu yang harus dipenuhi demi kemajuan bangsa serta terciptanya manusia Indonesia yang berkualitas. Pendidikan juga merupakan syarat mutlak yang harus dimiliki manusia dalam menjalani kehidupan di era globalisasi, begitu juga bagi warga negara Republik Indonesia. Pendidikan jugabertujuan untuk mencerdaskan kehidupan bangsa dan mengembangkan manusia seutuhnyadandapat menjadikan manusia yang berkualitas tentunya tidak akan terlepas dari unsur siswa itu sendiri. Hal ini disebabkan karena siswa merupakan salah satu komponen pendidikan yang menentukan dalam proses belajar mengajar

Tujuan pendidikan nasional adalah mencerdaskan kehidupan bangsa dan mengembangkan manusia Indonesia seutuhnya, yaitu manusia yang beriman dan bertaqwa terhadap Tuhan Yang Maha Esa dan berbudi pekerti luhur, memiliki pengetahuan dan keterampilan, kesehatan jasmani dan rohani, kepribadian yang mantap dan mandiri serta rasa tanggung jawab kemasyarakatan dan kebangsaan.

Sejalan dengan pengertian pendidikan diatas dalam Undang-Undang sistem Pendidikan Nasional No 20 Tahun 2003 ditegaskan lagi bahwa:Pendidikan adalah usaha sadar dan terencana untuk mewujudkan suasana belajar dan proses pembelajaran agar peserta didik secara efektif dapat mengembangkan potensi dirinya untuk memiliki kekuatan spiritual keagamaan, pengendalian diri, kepribadian, kecerdasan, akhlak mulia serta keterampilan yang diperlukan dirinya, masyarakat, bangsa dan dan Negara.

Menurut Slameto (2003: 54) keberhasilan belajar dipengaruhi oleh dua faktor,yaitu faktor internal dan fakto reksternal. Faktor internal adalah faktor yang ditimbulkan dari dalam diri individu terutama minat dan motivasi yang akan mendorong siswa untuk bersikap mandiri dalam belajar, sedangkan factor eksternal adalah faktor yang ditimbulkan dari kondisi yang berkembang di luar kehidupan pribadi anak, seperti lingkungan keluarga, lingkungan sekolah, dan masyarakat.

Menurut Hasan Basri (2011: 54) yang menyatakan bahwa salah satu faktor yang paling berpengaruh terhadap hasil belajar adalah kemandirian belajar siswa.Kemandiria nmerupakan salah satu aspek kepribadian yang sangat penting bagi individu.Individu yang memiliki kemandirian tinggi relative mampu menghadapi segala permasalahan karena individu yang mandiri tidak tergantung pada orang lain, selalu berusaha menghadapi dan memecahkan masalah yang ada.

Menurut Haris Mujiman (2007: 1) belajar mandiri adalah kegiatan belajar aktif, yang didorong oleh motif untuk menguasai sesuatu kompetensi, dan dibangun dengan bekal pengetahuan atau kompetensi yang telah dimiliki.Adapun faktor-faktor yang mempengaruhi kemandirian siswa dalam belajar yaitu faktor internal dan factor eksternal.Faktor internal adalah semua faktor yang bersumber dari dalam dirinya sendiri, seperti keadaan dan konstitusi tubuhnya sejak dilahirkan dengan perlengkapan yang melekat padanya. Faktor eksternal adalah semua keadaan atau pengaruh yang berasal dari luar dirinya, sering pula dinamakan dengan factor lingkungan

Keberhasilan proses pembelajaran ditandai dengan hasil belajar siswa yang baik. Menurut Hamalik (2008: 155) hasil belajar tampak sebagai perubahan tingkah laku pada diri siswa, yang dapat diamati dan diukur dalam bentuk perubahan pengetahuan, sikap dan keterampilan.

Hasil belajar siswa pada mata pelajaran ekonomi yang diperoleh siswakelas XI IPS di SMA N 1 Pariangan dapat dilihat pada Tabel berikut : 
Tabel 1: Persentase Tingkat Ketuntasan Siswa Pada Nilai Rapor Ekonomi Semester 2 SMA N 1 Pariangan Tahun Ajaran 2014-2015

\begin{tabular}{cccccccc}
\hline Kelas & KKM & $\begin{array}{l}\text { Rata- } \\
\text { rata } \\
\text { Kelas }\end{array}$ & Tuntas & $\%$ & $\begin{array}{l}\text { Tidak } \\
\text { tuntas }\end{array}$ & $\%$ & $\begin{array}{l}\text { Jumlah } \\
\text { siswa } \\
\text { (orang) }\end{array}$ \\
\hline XI IS 1 & 76 & 65,58 & 10 & $38 \%$ & 16 & $62 \%$ & 26 \\
XI IS 2 & 76 & 57,91 & 9 & $33 \%$ & 18 & $67 \%$ & 27 \\
XI IS 3 & 76 & 55,85 & 10 & $40 \%$ & 15 & $60 \%$ & 25 \\
XI IS 4 & 76 & 67,15 & 9 & $35 \%$ & 17 & $65 \%$ & 26 \\
\multicolumn{7}{l}{ Sumber: Guru Bidang Studi Ekonomi SMA N 1 Pariangan (2015) }
\end{tabular}

Pada tabel 1 di atas masih ada hasil belajar siswa yang belum sesuai dengan standar yang di tetapkan dalam SKBM (Standar Ketuntasan Belajar Minimal). Pada mata pelajaran Ekonomi di tetapkan standar nilai siswa diatas tujuh enam (76). Bagi siswa yang memperoleh nilai di bawah tujuh enam (76) berarti belum mencapai taraf ketuntasan dalam belajar.

Rendahnya hasil belajar siswa dipengaruhi oleh beberapa faktor, salah satunya

yaituiklimsekolahdankemandirianbelajar.

\section{METODE PENELITIAN}

penelitian ini adalah Penelitian deskriptif dan Asosiatif. Menurut Sugiyono (2012:10), penelitian deskriptif merupakan penelitian yang dilakukan untuk mengetahui atau mendeskripsikan nilai variabel mandiri, baik satu variabel atau lebih tanpa membuat perbandingan atau menghubungkan dengan variabel yang lain. Penelitian asosiatif merupakan penelitian yang bertujuan untuk mengetahui pengaruh atau hubungan antara dua variabel atau lebih.

Penelitian ini termasuk penelitian asosiatif karena bertujuan untuk mengetahui pengaruh atau hubungan antara dua variabel atau lebih yaitu untuk melihat seberapa besar pengaruhiklim sekolah dan kemandirian belajar terhadap hasil belajar siswa pada mata pelajaran ekonomi kelas XI IPS di SMA Negeri 1 Pariangan. Penelitian ini dilaksanakan di SMA Negeri 1 Pariangan Kabupaten Tanah Datar.

Populasi dalam penelitian ini adalah semua siswa kelas X1 IPS SMA Negeri 1
Pariangan yang terdaftar 2014/2015 sebanyak 104 orang. Teknik pengambilan sampel pada penelitian ini adalah Proporsional Random Sampling. Dalam penelitian ini jumlah sampel sebanyak 83 orang. Iklim sekolah dan kemandirian belajar diperoleh dari hasil penyebaran kuesioner yang telah diuji cobakan terlebih dahulu.

Penyusunan angket atau kuesioner berpedoman kepada skala likert dengan beberapa alternative jawaban dengan diberi bobot penilaian positif dan negatif, sedangkan hasil belajar (Y) diperoleh dari dokumentasi berupa nilai rapor kognitif mata pelajaran ekonomi semester II. Analisis yang digunakan dalam penelitian ini adalah analisis deskriptif dan analisis induktif yang terdiri dari uji maximum likelihood, uji ramsey, uji normalitas, uji heteroskedastisitas, uji multikolinieritas, uji autokorelasi, dan analisis regresi linear berganda.

\section{PEMBAHASAN}

\section{A. HasilBelajar (Y)}

$\begin{array}{cccr}\text { Dari } & \text { Tabel } 2 & \text { dapat } & \text { dilihat } \\ \text { bahwahasilbelajarsemester } & 2 & \text { mata }\end{array}$ pelajaran ekonomi siswa kelas XI IPS SMA Negeri 1 Pariangan diperoleh nilai rata-rata sebesar 60,07 , median 65 , modus 76 , standar deviasi 17,26 , maksimum 85 dan minimum 13 dimana kriteria ketuntasan nilai ekonomi pada kelas XI IPS SMA Negeri 1 Pariangan adalah 76. 
Tabel 2: Distribusi Frekuensi Hasil BelajarEkonomi (Y)kelas XI IPS SMA N 1 PARIANGAN

\begin{tabular}{|c|c|c|c|}
\hline \multirow{2}{*}{ No } & \multirow{2}{*}{ Kelas Interval } & \multicolumn{2}{|c|}{ Frekuensi } \\
\hline & & $\mathbf{F i}$ & $\%$ \\
\hline 1 & $13-21$ & 1 & 1,2 \\
\hline 2 & $22-30$ & 5 & 6,02 \\
\hline 3 & $31-39$ & 4 & 4,82 \\
\hline 4 & $40-48$ & 10 & 12,05 \\
\hline 5 & $49-57$ & 12 & 14,46 \\
\hline 6 & $58-66$ & 16 & 19,28 \\
\hline 7 & $67-75$ & 13 & 15,66 \\
\hline 8 & $76-84$ & 20 & 24,1 \\
\hline 9 & $85-93$ & 2 & 2,4 \\
\hline & Jumlah & 83 & 100 \\
\hline & Rata-rata & 60,07 & \\
\hline & Median & 65 & \\
\hline & Modus & 76 & \\
\hline & Standar Deviasi & 17,26 & \\
\hline & Maksimum & 85 & \\
\hline & Minimum & 13 & \\
\hline
\end{tabular}

Sumber: Olahan Data Primer, 2015

dari data diatas dapat kita ketahui bahwa hanya 22 orang siswa yang memiliki nilai diatas Kriteria Ketuntasan Minimum (KKM) dan 61 orang siswa memiliki nilai dibawah KKM. Hal ini membuktikan bahwa masih rendahnya hasil belajar siswa kelas XI IPS mata pelajran ekonomi SMA Negeri 1 Pariangan.

Tabel 3: Distribusi FrekuensiVariabel IklimSekolah

\begin{tabular}{cccccc}
\hline Variabel & Indikator & $\begin{array}{c}\text { No } \\
\text { Item }\end{array}$ & $\begin{array}{c}\text { Rata }- \\
\text { Rata }\end{array}$ & TCR & Keterangan \\
\hline & Tujuan sekolah & $1-3$ & 4,1 & 81,3 & Baik \\
& $\begin{array}{c}\text { Lingkungan sekolah } \\
\text { (fisik) }\end{array}$ & $4-10$ & 3,9 & 77,8 & Cukup \\
Iklim & Hubungan antar & $11-14$ & 3,3 & 65,8 & Cukup \\
Sekolah & personil sekolah & & & & Cukup \\
$\left(\mathrm{X}_{2}\right)$ & Pembelajaran efektif & $15-18$ & 3,2 & 64,6 & Baik \\
& Standar prestasi & $19-21$ & 4,1 & 82,2 & Cukup \\
& Kinerja personil & $22-24$ & 3,6 & 71,8 & Cukup \\
\hline
\end{tabular}

Sumber :Olahan data primer 2015

Selanjutnya berdasarkan tabel 3 diatas dapat dijelaskan bahwasecarakeseluruhan rata-rata skor jawaban responden untuk variabel iklim sekolah adalah sebanyak 3,7 dengan tingkat capaian responden sebesar $73,9 \%$ yang termasuk kategori cukup. Hal ini dapat dimakni bahwa secara keseluruhan bahwa 
iklim sekolah sebangai salah satu faktor yang harus diperhatikan.

Tabel4 :Distribusi frekuensiVariabelKemadirianBelajar

\begin{tabular}{cccccc}
\hline Variabel & Indikator & $\begin{array}{c}\text { No } \\
\text { Item }\end{array}$ & $\begin{array}{c}\text { Rata }- \\
\text { Rata }\end{array}$ & TCR & Keterangan \\
\hline \multirow{3}{*}{ Kemandiria } & Bebas berinisiatif & $1-5$ & 3,3 & 66,0 & Cukup \\
n Belajar & Percaya diri & $6-11$ & 4,1 & 81,2 & Baik \\
$\left(\mathrm{X}_{3}\right)$ & Bersifat original & $12-13$ & 4,4 & 88,0 & Baik \\
& Mencoba sendiri & $14-17$ & 2.7 & 54,0 & Kurang \\
\cline { 2 - 6 } & Total & & $\mathbf{3 , 8}$ & $\mathbf{7 5 , 5}$ & Cukup \\
\hline
\end{tabular}

Sumber :Olahan data primer 2015

Berdasarkan tabel 4 diatas dapat dijelaskan bahwa secarakeseluruhanratarata skor jawaban responden untuk variabel kemandirian belajar adalah sebanyak 3,8 denga tingkat capaian responden sebesar $75,5 \%$ yang termasuk kategori cukup. Hal ini dapat dimakni bahwa secara keseluruhan bahwa kemandirian belajar pada mata pelajaran ekonomi kelas XI IPS SMA Negeri 1 Pariangan dikategorikan cukup.

\section{PEMBAHASAN}

Pengaruhiklimsekolah terhadap hasil belajar ekonomi siswa kelas XI IPS SMA Negeri 1 Pariangan. Berdasarkan hasil analisis data dan pengujian hipotesis yang telah dilakukan, diperoleh hasil bahwa iklim sekolah berpengaruh positif dan signifikan terhadap hasil belajar ekonomi siswa kelas XI IPS SMA Negeri 1 Pariangan. Hal ini ditunjukan oleh nilai koefesien regresi sebesar 0,244 dan nilai tsebesar 4,184 $>t_{\text {tabel }} 1,99045$ ini berarti $H_{a}$ diterima $H_{o}$ ditolak dengan demikian dapat dikatakan bahwa terdapat pengaruh positif dan signifikan secara parsial antara iklim sekolah terhadap hasil belajar siswa kelas XI IPS SMA Negeri 1 Pariangan. Hal iniberartiSemakinbaik iklim sekolah maka akan semakin baik pula hasil belajar yang diperoleh oleh siswa tersebutdanbegitujugasebaliknya.

MenurutMulyasa (2011:90) iklim sekolah yang kondusif mendorong setiap warga sekolah untuk bertindak dan melakukan sesuatu yang terbaik yang mengarah pada hasil belajar siswa yang tinggi. Iklim sekolah juga berkaitan denganpemupukan harapan untuk berprestasi pada semua warga sekolah.

Penelitian ini juga sejalan dengan penelitian yang dilakukan oleh Susi Lestari (Skripsi, 2007) tentang pengaruh Iklim Sekolah dan Komitmen Siswa Terhadap Hasil Belajar Pada Mata Pelajaran Akuntansi Kelas XI IS di SMA N 4 Sungai Penuh, yang mana hasil penelitiannya menyatakan bahwa iklim sekolah dan komitmen siswa berpengaruh signifikan terhadap hasil belajar pada mata pelajaran akuntansi kelas XI IS di SMA N 4 Sungai Penuh. Jadi pengaruh iklim sekolah terhadap hasil belajar sangat penting karena iklim sekolah yang baik dapat memberikan pengaruh yang baik terhadap hasil belajar.

Pengaruh kemandirian belajar terhadap hasil belajar ekonomi siswa kelas XI IPS SMA Negeri 1 Pariangan. Berdasarkan hasil analisis data dan pengujian hipotesis yang telah dilakukan, diperoleh hasil bahwa kemandirianbelajar berpengaruh positif dan signifikan terhadap hasil belajar ekonomi siswa kelas XI IPS SMA Negeri 1 Pariangan. Hal ini ditunjukan oleh nilai koefesien regresisebesar 0,163 dan nilai $t_{\text {hitung }}$ sebesar 2,371 $>t_{\text {tabel }} 1,99045$ ini berarti $H_{a}$ diterima $H_{o}$ ditolak dengan demikian dapat dikatakan bahwa terdapat pengaruh positif dan signifikan secara parsial antara kemandirian belajar terhadap hasil belajar siswa kelas XI IPS SMA Negeri 1 Pariangan.Hal iniberarti semakin 
baik kemandirianbelajarsiswa maka akan semakin baik pula hasil belajar yang diperoleh oleh siswa tersebutdanbegitujugasebaliknya.

Menurut Nursobah

"kemandirian merupakan karakter personal yang dapat membuat dan mempertanggungjawabkan keputusan sendiri, ditunjukkan dalam kebiasaankebiasaan proaktif, yaitu menetapkan tujuan yang hendak dicapai dan mendahulukan yang utama". Artinya,kemandirian merupakanperilakuyangaktivitasnyadiarahk anpadadirisendiri,tidakmengharapkan bantuan dari orang lain dan mampubertanggung jawab terhadapkeputusan yang telah di ambil.

Hal ini didukung oleh penelitian Risnayeli (2008) yang menyatakan bahwa terdapat hubungan yang positif antara kemandirian belajar terhadap hasil belajar. Kemandirian belajar berperan penting dalam proses pembelajaran. Disini siswa diminta untuk lebih aktif dalam belajar tidak hanya mengandalkan ilmu dari guru saja. Hal ini dapat membantu siswa untuk lebih kreatif dan memiliki inisiatif. Selain itu kemandirian belajar juga mendorong siswa untuk bersaing meningkatkan hasil belajarnya.

\section{PENUTUP}

Iklim sekolah berpengaruh positif dan signifikan terhadap hasil belajar ekonomi siswa kelas XI IPS SMA Negeri 1 Pariangan. Yang ditunjukan oleh nilai koefisien regresi sebesar 0,244 dant $t_{\text {hitung }}$ sebesar 4,184 $>t_{\text {tabel }} 1,99045$ ini berarti $H_{a}$ diterima $H_{o}$ ditolak.

kemandirian belajar berpengaruh positif signifikan terhadap hasil belajar ekonomi siswa kelas XI IPS SMA Negeri 1 Pariangan. yang ditunjukan oleh nilai koefesien regresisebesar 0,163 dan nilai $t_{\text {hitung }}$ sebesar 2,371 $>t_{\text {tabel }} 1,99045$ ini berarti $H_{a}$ diterima $H_{o}$ ditolak.

\section{DAFTAR PUSTAKA}

10.22202/economica.2016.v4.i2.634

Fathurrohman \& Sobry Sutiko. (2011). Strategi Belajar Mengajar. Bandung: PT. Refika Aditama.

Febrina, Silvia (2011). pengaruh pengelolaan kelas dan motivasi mengajar guru terhadap hasil belajar siswa pada mata pelajaran ekonomi SMA di Kota Bukittinggi. Skripsi: UNP Padang.

Hamalik, Oemar. 2008. Perencanaan Pengajaran Berdasarkan Pendekatan. Jakarta : Bumi Aksara

Mujiman, Haris. 2007.

ManajemenPelatihanBerbasisbelajarMand iri.Yogyakarta :Pustaka Pelajar.

Lestari, Susi (2007). pengaruh iklim sekolah dan komitmen siswa terhadap hasil belajar siswa pada mata pelajaran Akuntansi kelas XI IPS di SMA $N 4$ Sungai Penuh. Skripsi: UNP Padang

Mulyasa (2011). Manajemen dan Kepemimpinan Kepala Sekolah. Jakarta: PT. Bumi Aksara

Nursobah, Asep (2009). Hubungan antara Kemandirian Belajar,Komunikasi Interpersonal dan Identitas Sosial dengan Hasil Belajar. Jurnal Teknologi Pendidikan Vol. 11 No.1

Risnayeli (2011). pengaruh kreativitas dan kemandirian belajar terhadap hasil belajar mata pelajaran kewirausahaan siswa kelas XI pada SMK N 3 Padang. Skripsi: UNP Padang

Slameto. 2003. Belajar Dan Faktor-Faktor yang Mempengaruhinya. Jakarta: Rineka Cipta.

Usman, Mohammad Uzer. (2009). Menjadi Guru Profesional. Bandung: PT. Remaja Karya Rosda. 